\title{
Study on the Conversion of Carbon Dioxide by Microwave Plasma Technology \\ YuQiong $\mathrm{Wu}^{1, \mathrm{a}}$
}

${ }^{1}$ School of Chemistry and Environmental Engineering, Jianghan University, HuBei, Wuhan, 430056, China

a99067410@qq.com

Keywords: Microwave; Plasma; Carbon dioxide; Transformation

\begin{abstract}
Carbon dioxide as the final oxidation product of carbon and carbon containing compounds, whether it is from the comprehensive utilization of carbon resources, but also from environmental pollution control, the research and development of its transformation and utilization has a very important significance. In this paper, the microwave plasma body technology is applied to the conversion of carbon dioxide. $\mathrm{H}_{2} / \mathrm{CO}_{2}$ ratio, $\mathrm{CO}_{2}$ flow rate and microwave power on the influence of carbon dioxide conversion rate are studied. The results show that the $\mathrm{CO}_{2}$ conversion rate is $88.6 \%$ in the reaction conditions of $\mathrm{H}_{2} / \mathrm{CO}_{2}$ ratio 0.5 and $\mathrm{CO}_{2}$ volume flow $120 \mathrm{ml} / \mathrm{min}$ and microwave power $120 \mathrm{~W}$. Microwave plasma technology for carbon dioxide conversion is a kind of green and effective method.
\end{abstract}

\section{Introduction}

Carbon dioxide in the atmosphere is increasing, although it is a greenhouse gas, the environment of human survival has caused the accumulation of the serious damage, but it is also a valuable $\mathrm{C} 1$ resources, if it can reasonably develop the use of $\mathrm{CO}_{2}$, not only to control environmental pollution, greenhouse effect, but also the comprehensive utilization of carbon resources are significant. However, $\mathrm{CO}_{2}$ is a stable compound, the focus of our research is on how to turn it into high value-added products.

Plasma technology has been used in chemical reactions, such as the promotion, esterification, hydrolysis, oxidation and so on[1]. The technology is also applied in environmental management, waste gas treatment, sewage detection and solid waste. The use of radio frequency plasma technology for $\mathrm{CO}_{2}$ transformation has been reported[2-5], and this paper uses microwave plasma technology, through the microwave energy to stimulate the gas molecules group and generate plasma, activation and recombination into a new value of the compound, so as to achieve the purpose of $\mathrm{CO}_{2}$ transformation.

\section{Materials and Equipment}

Microwave plasma equipment (self made processing), Gas chromatograph (Shanghai Precision Scientific Instrument Co., ltd.), Rotor flow meter (Yuyao Yinhuan flowmeter Co. ltd.), Carbon dioxide (Wuhan heaven sent Gas Co., Ltd.), Hydrogen (Wuhan heaven sent Gas Co., Ltd.).

\section{Experiment Technology}

Schematic diagram of the process is shown in Figure 1. Microwave plasma equipment uses microwave to excite the thin gas discharge, which can produce plasma. The vacuum chamber is $50 \mathrm{~mm}$ diameter quartz tube cavity, which are arranged at both ends of double water to cool down the protective sleeve. The vacuum system of the device adopts 2 XZ-2 type rotary vane vacuum pump, and the mechanical pump and the vacuum chamber are provided with the electromagnetic valve and the high vacuum diaphragm valve, the bypass pipe is set up to the other valve to facilitate the operation safety of the vacuum system and the flexible control of the reaction gas pressure. 
The process uses the rotor flow meter to control the $\mathrm{H}_{2}$ and $\mathrm{CO}_{2}$ intake, and the $\mathrm{CO}_{2}$ and $\mathrm{H}_{2}$ are mixed evenly into the microwave plasma reaction chamber. When the air flow is stable, the voltage and the microwave power can be adjusted for plasma reaction. The reaction products are in the gas phase chromatograph for online analysis. The $\mathrm{CO}_{2}$ conversion rate can be calculated according to the analysis results. The calculation formula for the conversion rate of carbon dioxide is as follows:

$$
X_{\mathrm{CO} 2}=\left(1-\frac{n_{\mathrm{CO} 2}}{n_{\mathrm{CO} 2}^{0}}\right) \times 100 \%
$$

$n_{\mathrm{CO} 2}$ - The amount of carbon dioxide after the reaction

$n_{\mathrm{CO} 2}^{0}$-The amount of carbon dioxide before the reaction.

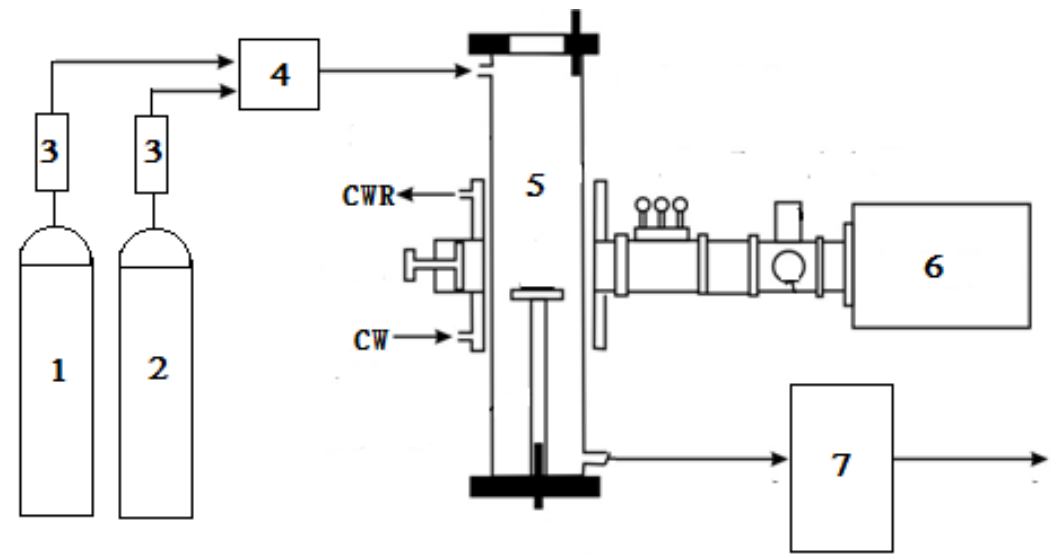

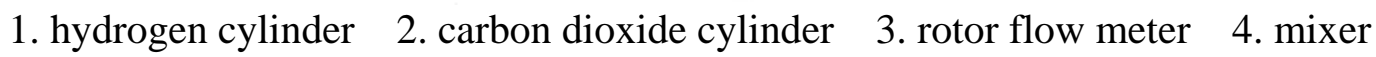

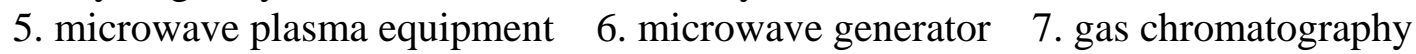

Fig. 1 Schematic diagram of process

\section{Reaction mechanism}

Reactions of carbon dioxide and hydrogen in the plasma devices are shown below:

$$
\begin{gathered}
\mathrm{e}+\mathrm{CO}_{2} \longrightarrow \mathrm{CO}+\mathrm{O}^{-} \\
e+\mathrm{CO} \longrightarrow \mathrm{C}+\mathrm{O}^{-} \\
\mathrm{O}^{-}+\mathrm{O}^{-} \longrightarrow \mathrm{O}_{2}+2 e \\
\mathrm{O}^{-}+\mathrm{O}^{-}+\mathrm{O}^{-} \longrightarrow \mathrm{O}_{3}+3 e \\
\mathrm{H}_{2} \stackrel{e}{\longrightarrow} \mathrm{H}+\mathrm{H} \\
\mathrm{H}+\mathrm{H}+\mathrm{O} \longrightarrow \mathrm{H}_{2} \mathrm{O}
\end{gathered}
$$

\section{Effect of $\mathrm{H}_{2} / \mathrm{CO}_{2}$ volume ratio on conversion rate}

Under certain microwave power and feed rate, the effect of the $\mathrm{H}_{2} / \mathrm{CO}_{2}$ volume ratio on the conversion rate is investigated. The results are shown in Fig 1.

The experimental results show that with the increase of $\mathrm{H}_{2} / \mathrm{CO}_{2}$ volume ratio, the conversion rate of the corresponding $\mathrm{CO}_{2}$ is gradually increasing. This is because in the plasma conditions, the ground state hydrogen molecules are excited by high energy electron collisions, which are excited state of the hydrogen molecules and hydrogen atoms, while the high energy electrons and the excited state of hydrogen and hydrogen atom is the main active ion of $\mathrm{CO}_{2}$ dissociation. When the content of $\mathrm{H}_{2}$ increased and the content of $\mathrm{CO}_{2}$ is decreased, the content of hydrogen in the plasma increased, which is favorable for the conversion of $\mathrm{CO}_{2}$, and the conversion rate of $\mathrm{CO}_{2}$ increased. Of course, the amount of $\mathrm{H}_{2}$ is not too large, can meet the transformation of $\mathrm{CO}_{2}$, so the $\mathrm{H}_{2} / \mathrm{CO}_{2}$ 
volume ratio is 0.5 .

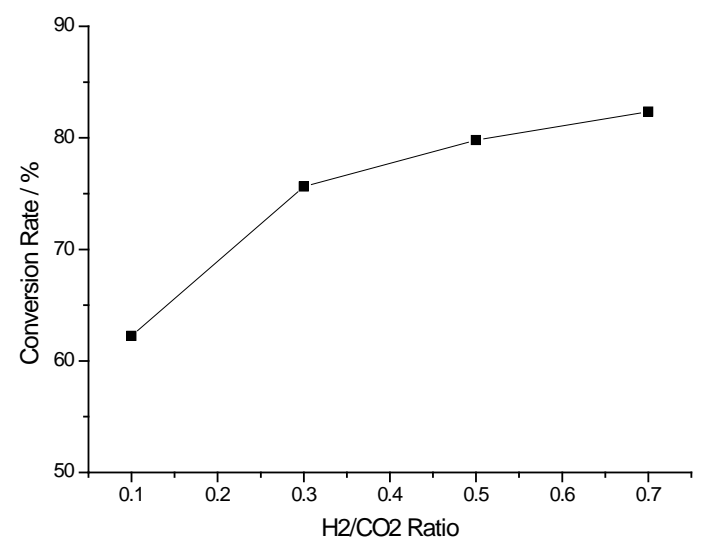

Fig. 1 Effect of $\mathrm{H}_{2} / \mathrm{CO}_{2}$ volume ratio on conversion rate

\section{Effect of $\mathrm{CO}_{2}$ flow on conversion rate}

In a certain microwave power and $\mathrm{H}_{2} / \mathrm{CO}_{2}$ ratio of 0.50 , the effect of $\mathrm{CO}_{2}$ gas flow rate on the reaction conversion is investigated. As shown in Fig 2. The results show that the conversion rate of carbon dioxide decreases with the increase of gas flow rate. This is because the size of the reaction gas flow is directly related to the size of the energy density, but also related to the vacuum degree of the reaction zone. Under certain input power, the greater the flow, the smaller the energy density, the smaller the vacuum degree, and the less the activation and conversion reaction. That is to say, the smaller the flow, the longer the residence time, the number of free radicals generated by $\mathrm{CO}_{2}$ dissociation is more, the conversion rate is also increased; the larger the flow rate, the shorter the residence time, the less the number of free radicals generated by $\mathrm{CO}_{2}$, and the conversion rate will be reduced. Therefore, the $\mathrm{CO}_{2}$ gas flow rate is $120 \mathrm{~mL} / \mathrm{min}$.
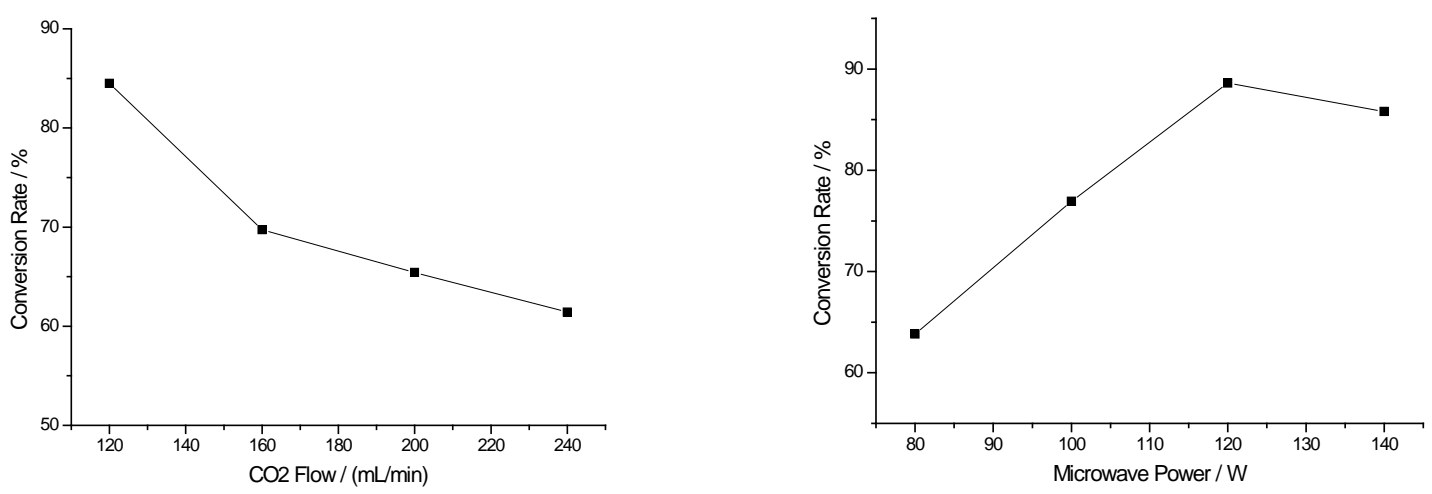

Fig. 2 Effect of $\mathrm{CO}_{2}$ flow on conversion rate Fig. 3 Effect of microwave power on conversion rate

\section{Effect of microwave power on conversion rate}

At $\mathrm{CO}_{2}$ flow rate of $120 \mathrm{ml} / \mathrm{min}$, and $\mathrm{H}_{2} / \mathrm{CO}_{2}$ ratio of 0.5 , the conversion rate of microwave power to $\mathrm{CO}_{2}$ is investigated, as shown in Fig 3. From Fig 3 shows that with the increase of microwave power, the conversion rate of $\mathrm{CO}_{2}$ is obviously improved, but to further improve the microwave power, the conversion rate of $\mathrm{CO}_{2}$ can be reduced. This is because of the increase of the microwave power, the number of high energy electrons generated in the plasma region increases, and the probability of $\mathrm{CO}_{2}$ and $\mathrm{H}_{2}$ collisions in the high energy electron and the system is increased. Therefore, with the increase of microwave power, the conversion rate of $\mathrm{CO}_{2}$ is increasing. 
However, with the increase of the microwave power, the volume concentration of $\mathrm{H}_{2} \mathrm{O}$ and $\mathrm{CO}$ in the system is increasing also, which causes the increase of the $\mathrm{CO}$ molecule and the $\mathrm{O}$ atom to generate the $\mathrm{CO}_{2}$. So the power is increased to a certain extent, and then increase the discharge power, the conversion rate of $\mathrm{CO}_{2}$ becomes very small. Microwave power was $120 \mathrm{~W}$, the conversion rate of carbon dioxide was $88.6 \%$.

\section{Conclusion}

Microwave plasma technology is applied to the conversion of carbon dioxide gas. The effects of $\mathrm{H}_{2} / \mathrm{CO}_{2}$ ratio, $\mathrm{CO}_{2}$ flow and microwave power on the conversion of $\mathrm{CO}_{2}$ are studied. The results show that: with the increase of $\mathrm{H}_{2} / \mathrm{CO}_{2}$ volume ratio, the conversion rate of $\mathrm{CO}_{2}$ increases gradually, but the amount of $\mathrm{H}_{2}$ is not too large, it can meet the transformation of $\mathrm{CO}_{2}$, so the $\mathrm{H}_{2} / \mathrm{CO}_{2}$ volume ratio is 0.5 ; The conversion rate of carbon dioxide decreases with the increase of gas flow rate, so the $\mathrm{CO}_{2}$ gas flow rate is $120 \mathrm{~mL} / \mathrm{min}$; With the increase of microwave power, the conversion rate of $\mathrm{CO}_{2}$ was significantly improved, However, with the further improvement of microwave power, the conversion rate of $\mathrm{CO}_{2}$ can be decreased, so the microwave power is $120 \mathrm{~W}$. Therefore, the optimal reaction condition is that the $\mathrm{H}_{2} / \mathrm{CO}_{2}$ ratio is 0.5 , the volume flow rate of $\mathrm{CO}_{2}$ is $120 \mathrm{ml} / \mathrm{min}$, the microwave power is $120 \mathrm{~W}$, the conversion rate of $\mathrm{CO}_{2}$ is $88.6 \%$.

Microwave plasma technology is used in the conversion of carbon dioxide gas, which has the advantages of mild conditions, convenient operation and high conversion rate. So it is a kind of green new method. Of course, this paper is only a preliminary study on the conversion of $\mathrm{CO}_{2}$ by microwave plasma technology, which has further optimized space, such as adding catalyst, orthogonal experiment design, and so on. It is believed that this method will be widely used in the transformation of $\mathrm{CO}_{2}$.

\section{Acknowledgement}

In this paper, the research was sponsored by Jianghan University graduate course construction project in 2014 (Project No. 04200021).

\section{References}

[1] Zhao Qing, Liu Shuzhang, Tong Honghui. Plasma technology and its Applications [M], Beijing: National Defend Industry Press, 2009.

[2] SUN Jinliang. Study on $\mathrm{CO}_{2}$ Rediction Driving by Low Temperature Plasma [D]. Qingdao: Qingdao University of Science \& Technology, 2013

[3] ZHOU Juncheng, YIN Yanhua, ZHENG Hanyong, XU Yue, ZHOU Xu, GONG Junsong. Reduction of $\mathrm{CO}_{2}$ to $\mathrm{CO}$ Using $\mathrm{CO}_{2}-\mathrm{H}_{2}$ Non-wquilibrium Plasma Method [J]. High Voltage Engineering, 201238 (5) 1065-1069.

[4] TAN Shi-yu, YANG Da-wei. Study on the conversion of carbon dioxide and hydrogen by RF-discharge plasma[J]. Natural Gas Chemical Industry, 200833 (5) 23-26

[5]Yang Dawei. Study on Carbon Dioxide Hydrogenation Conversion Using Cold Plasma Reaction under Radio-Frequency (RF) Discharge[D]. Chongqing: Chongqing University, 2008 